\title{
New Directions in Fieldwork Education: Using PDAs in Town Planning
}

\author{
Takaharu MIYOSHI*, Hideki UESHIMA**, Hiroshi MORIYASU**, Yoshitaka AOYAMA**
}

\begin{abstract}
In recent years, town planning has increasingly focused on regional history and culture. The education of town planning students now emphasizes such factors, particularly in fieldwork education where we are looking for more efficient and effective ways of doing research. Our students prepared a report emphasizing local culture in an effort to develop an ideal plan for a historically significant region - a post town that prospered during the Edo period (1603-1867). The town has changed greatly because of the reclamation of coastal areas and the loss of buildings burned during a conflagration in the Edo period. The "town that had been lost" was experienced by walking through the area using a PDA input with a current map of the coastline and/or an old map drawing from the Edo period. Of special significance is the software we developed for the PDA that was used by students. This paper describes the functions of the software, the fieldwork that was performed, and what this study should contribute to the region.
\end{abstract}

Keywords: fieldwork, development of PDA software, region's history and culture, town planning, promoting students

\section{INTRODUCTION}

In our country, esthetically pleasing town planning that makes ample use of local history and culture has assumed greater importance, including, in particular, the value of old private houses and the traditional townscapes left in each district. For example, old merchant houses called machiya with local, traditional characteristics are saved and often restored, and are now regarded as a key component of town planning. The preservation of old towns in Japan took a positive step forward in the 1970's. More recently, the law concerning maintenance and the improvement of historical scenic beauty in the region (Historical City Planning Law) was enforced in a related situation on November 4, 2008; many historical towns will be better protected from now on. Having said this, however, we know that not all town planning efforts are successful. Clearly, the motivations and abilities of planning team leaders is one of the keys of success.

In academic education, the importance of on-theground experience can not be overemphasized; thus, we have found that a practicing study, such as fieldwork and workshops, is critical to the professional advancement of students of town planning. We present students with a concrete problem and expect them to acquire the necessary knowledge and technology through the study to solve it. The purpose of this research is to a) develop software for PDA (equipped with GPS) as an educational supporting tool in the conduct of fieldwork, and b) search for new and more effective fieldwork methods. More specifically, students are expected to learn about the natural environment in the region, people's lifestyles, culture, and history, which enables them to make better planning decisions. Another dimension of the research described here, which was designed to aid in student development, was to develop a plan of improvement for the region.

Our department's educational plan for a town planner's development and advancement involves three major areas:

1) Fieldwork in history and culture

As an educational plan of fieldwork, students collect and analyze material concerning the history and the

* Member of JSET, Department of Regional Environment Studies, Faculty of Environmental Studies, Hiroshima Institute of Technology, $\bar{\top}$ 731-5193 Miyake,Saeki-ku,Hiroshima Japan Tel:082-921-9011.

** Department of Regional Environment Studies, Faculty of Environmental Studies,Hiroshima Institute of Technology, $\bar{T}$ 731-5193, Miyake,Saeki-ku,Hiroshima Japan. 
culture that are handed down to us from ancestors.

2) Fieldwork in townscape plan

This activity aims at the reproduction of the region. Students learn how to grasp the current state of the region and to plan maintenance-basis policy to preserve the environment or to make ideal towns.

3) Fieldwork in regional social planning and management

Students study an environmental element, a feature that incorporates the natural environment in the region, its historical transition, and an environmental problem. In this paper we present two specific examples describing fieldwork using PDA that we conducted according to these plans. The location of the fieldwork was the area surrounding the Honjin (a place of lodging for local loads and other assistants) in Hatsukaichi City, which is west of Hiroshima City. The main road called the West Country Highway passed through there during the Edo period; and Hatsukaichi had prospered with lots of machiyas along the road as a stopping place for travelers. There are also some Shinto shrines and Buddhism temples. The history here has been researched actively. Miyajima is one of three famous Japanese Scenic Wonders and a World Heritage Site. It is near Hatsukaichi and our Institute of Technology, making it very convenient for students to study. Unfortunately, two thirds of the town's buildings were destroyed by fire at the end of the Edo period. There are very few old, traditional buildings and houses remaining in this region. The coastline of the Edo period and the coastline nowadays are different largely because land has been reclaimed from the sea to construct new roads and houses. It should be noted, however, that three historical drawings from the Edo period still exist: the Kanbun Drawing (1661 1672), Syotoku Drawing (1711 1715), and Machiya Drawing (1808). The historical image of the townscape is still present in the current townscape. We see that each machiya was built on long narrow plots of ground, that is, characteristically with short frontage but considerable depth. We can visualize the post town of the Edo period, one with numerous machiyas standing along the West Country Highway.

Students tasked with reconstructing the townscape of the post town drawn in the Machiya Drawing made ample use of local history. They studied how to conduct interviews, analyze historical documents, and present their findings and compare notes at a workshop with local expert historians. In these situations, fieldwork training was especially important. One characteristic of student fieldwork training is searching the coastline in the Edo period, and another is actually "walking" in the Machiya Drawing. The software developed for the fieldwork was both efficient and effective.

Previous work using PDAs in support of learning, studying and educational fieldwork is cited in Abe et al. (2004), Chen and Hsu (2006), Feng et al. (2006) and Mimura et al. (2004). In the remainder of the paper, we discuss the PDA we used in our research, and the function of software developed for the PDA itself (Section 2 ); we conclude by describing the fieldwork that was conducted for the study (Section 3).

\section{PDA USED FOR FIELDWORK}

Most of the available software developed for the PDA is for use in navigation. Some software for PDA has the function of inputting information using a pen to draw figures and/or text on the map in PDA similar to that of an electric organizer. In order to conduct fieldwork according to our educational plans, we needed software with the capability to store any maps in the PDA, to set items of investigation in the PDA, and to get the necessary information to the fieldwork site in an efficient manner. We explain about the main functions of the software in section 2.1, and about the accuracy of GPS in section 2.2.

\subsection{Main function of software for PDA}

In the paragraphs that follow we discuss the function of the software for PDA that we carry at the stage of fieldwork performance and the PC software that we use both at the fieldwork preparation stage and the post- 

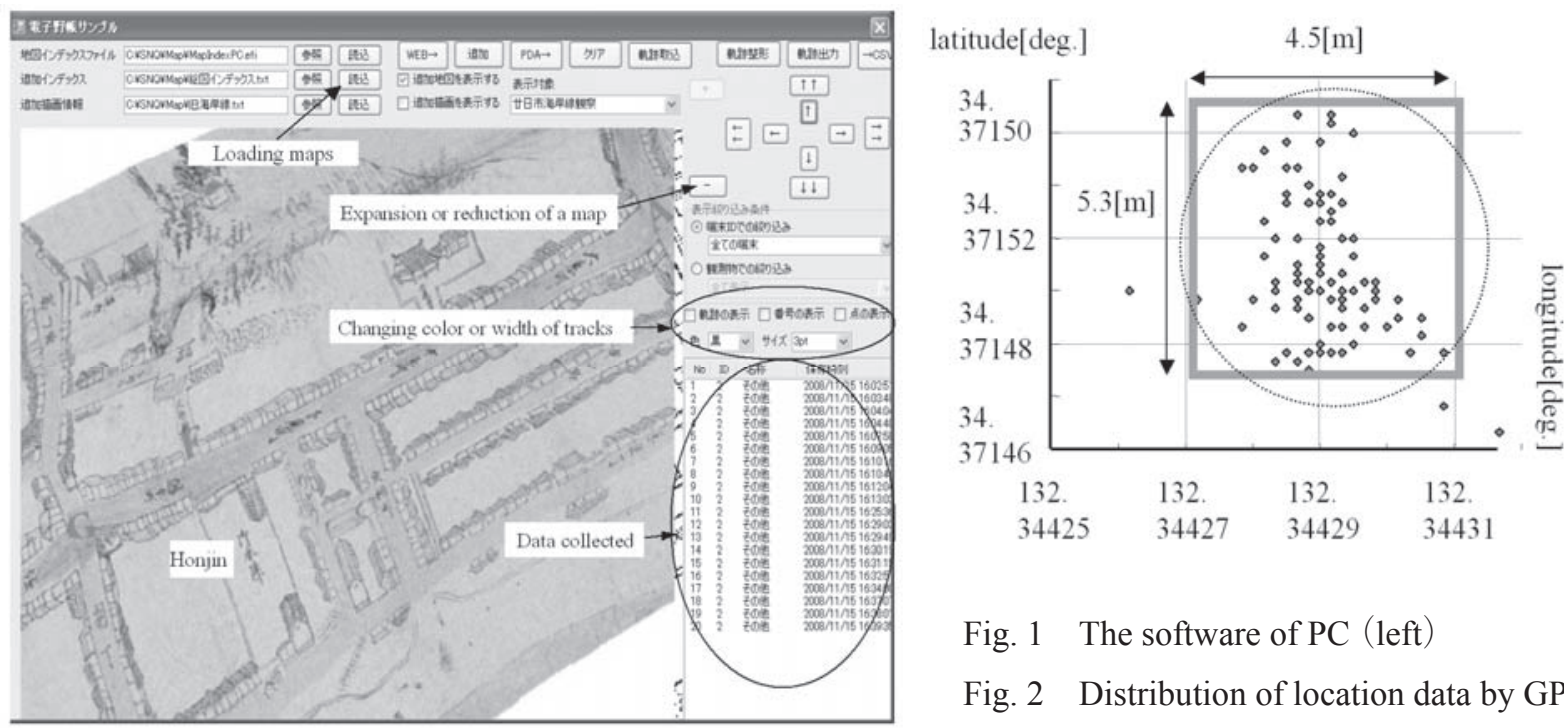

Fig. 1 The software of PC (left)

Fig. 2 Distribution of location data by GPS

fieldwork stage.

(1) The fieldwork preparation stage

In preparation for fieldwork, we begin by using PC in the classroom, for example storing maps and setting items of investigation into PDA. The software that we developed for PC is used at this stage. The main functions of the software are follows, (a) the maps are stored into PDA. In this context we need to make special mention of the availability of historical drawings -- old maps drawn during the Edo period which were invaluable in our work. (b) Adding the needed lines to the map data.

(c) Setting items of investigation before doing fieldwork.

(2) The fieldwork performance stage

PDA is used outdoors at this stage using the software we developed. The main functions are (a) Collecting data. (b) Inputting handwritten text by using a pen on the PDA display and (c) Recording automatically the route that the investigator walks.

(3) The post-fieldwork stage

We developed PC software which has following functions: The function that takes the data collected by PDA in to $\mathrm{PC}$, and the function that shows the result of the investigation and the route of the investigator on the PC display (Fig. 1).

\subsection{Accuracy of GPS contained in the PDA}

In this section, we describe just the accuracy of GPS itself. The discussion about the accuracy of the position where an investigator is on the map, as to whether the position of the investigator on the map corresponds to the position of the real place or not, is described in section 3.2 using the data from the route we walked in the fieldwork.

The PDA that was used to assess the GPS's accuracy was positioned on the terrace of the fifth floor, which is open to the northeast. Information on location expressed as latitude and longitude is recorded every 30 seconds from 1:06 p.m. to 1:31 p.m. Fig. 3 shows 50 positional data points. They scatter in the area that is a rectangle and circle drawn in Fig.2 because of the error of GPS. The unit of the distance is shown by $[\mathrm{m}]$ as we interpret the size of the error. Most measurements exist in the area of a circle where the radius is about $3.7[\mathrm{~m}]$. We have to take into account the size of the error when we analyze the data that were obtained by the PDA.

\section{APPLYING PDA TO FIELDWORK}

Two specific examples are presented describing our fieldwork using PDA. One is a coastline inquiry of the Edo period in the subject region. This was an investigation to find evidence as to where the coastline was at that time. The second is fieldwork to determine the degree to which a location on a present map corresponds to that on a map drawn in the Edo period. These examples of fieldwork are both for historical inquiry, and are conducted to 


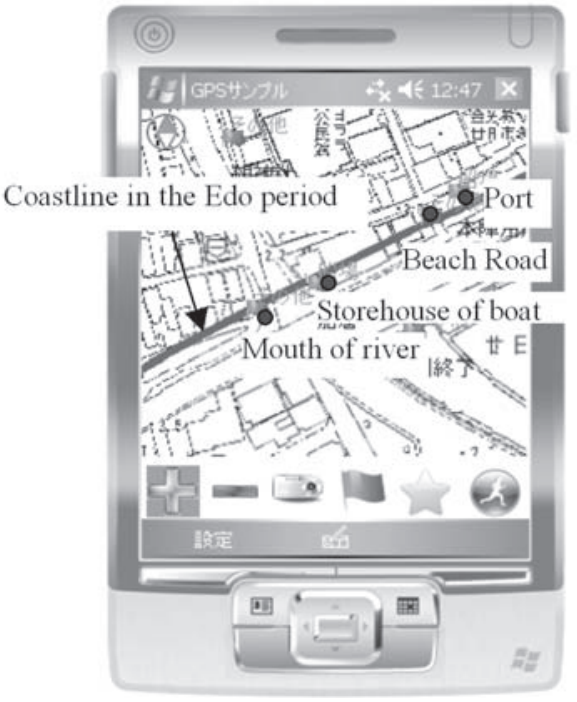

Fig. 3 A part of the result of the survey

provide students with experience about the Edo period. It should be noted that both studies were conducted with the valuable assistance of members of the Hometown Cultural Society who explained the history of the region to participants. They also answered some questions raised by the students.

\subsection{Coastline inquiry fieldwork}

This fieldwork corresponds to numbers 1) $~ 3$ ) in the educational plans described in the Introduction.

\subsubsection{The fieldwork we conducted}

This Coastline inquiry fieldwork done by the students to study was a) to get a true image of machiya design based on the Machiya Drawing that was sketched in 1808 during the Edo period, and b) to clarify regional characteristics at that time and identify some problems to be solved in the region by considering its current state. As noted earlier, the current coastline has receded a large distance because of reclamation activities.

What we wanted to know was the position of the coastline in the Edo period. We already had some knowledge of the coastline from material that was issued by the West Country Highway Restoration Project; our mission was to find physical evidence or signs where the coastline was at that time. The line that shows the position of the presumed coastline drawn on the PDA map was entered for fieldwork.

Items of investigation entered in the PDA included a) port, b) lighthouse, c) place name, d) the name of the temple or shrine, e) information such as coastal beach sand, shells, etc. Such items can be inputted easily at the fieldwork site by just selecting the item of investigation. When other information is obtained that is not preset as an item of investigation, we can input it on the display by a hand-written character using a pen.

Some items are quite helpful. We know, for that a port or lighthouse is always near a coastline. Names of shrines or temples also provide critical information. A Sumiyoshi Shrine (designed for prayers for the safety of ships and fishermen) was always constructed at seaside. Also the word "Cho-on" of Cho-onji Temple means the sound of the sea waves. So Cho-onji Temple means a temple where we can hear the sound of the sea. In addition, names of places such as Hama, which has the meaning of seashore and Uodana (fish market) are closely associated with the sea and must have been nearby in the Edo period. We also found a part of a stone wall built along the coastline that was designed to prevent damage from high tides and found the place where sand and gravel were scooped up. Fig. 3 shows part of the evidence that we find.

\subsubsection{Evaluation of the fieldwork}

Of primary importance to this fieldwork is that we could use the PDA map of the presumed coastline.

More specifically, investigators had the capability of knowing where they were and where the presumed coastline was by PDA; simply stated, they couldn't miss their current position and the area they were supposed to investigate. Information gathered during this process could be stored efficiently in the PDA because the items of investigation had already been prepared for use in PDA. Referring again to Fig. 3, note that the bold line is a coastline, and the symbol of a black circle shows the position where evidence was found. In essence, we had 


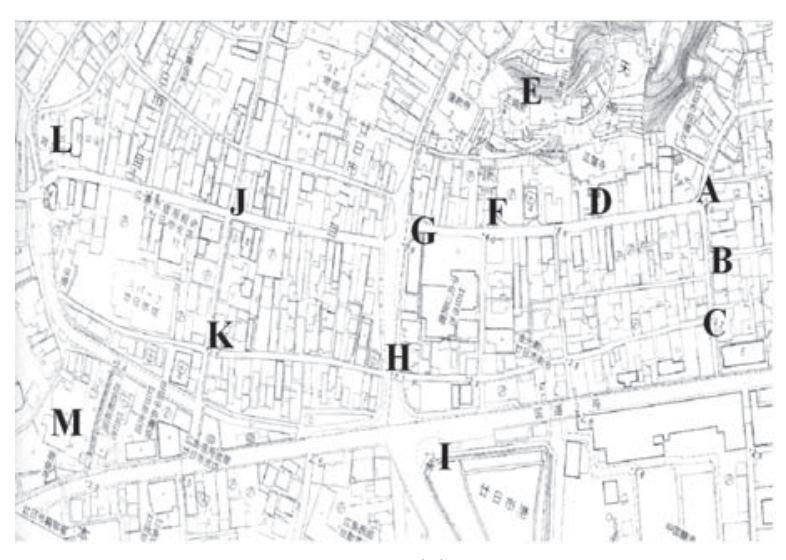

(a)

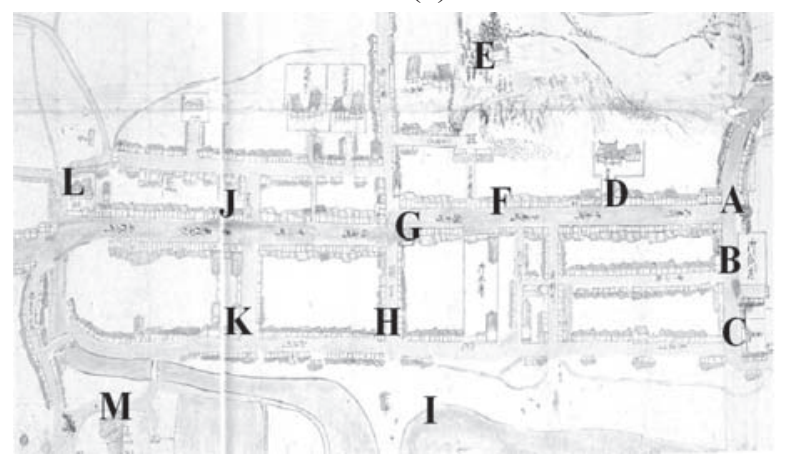

(b)

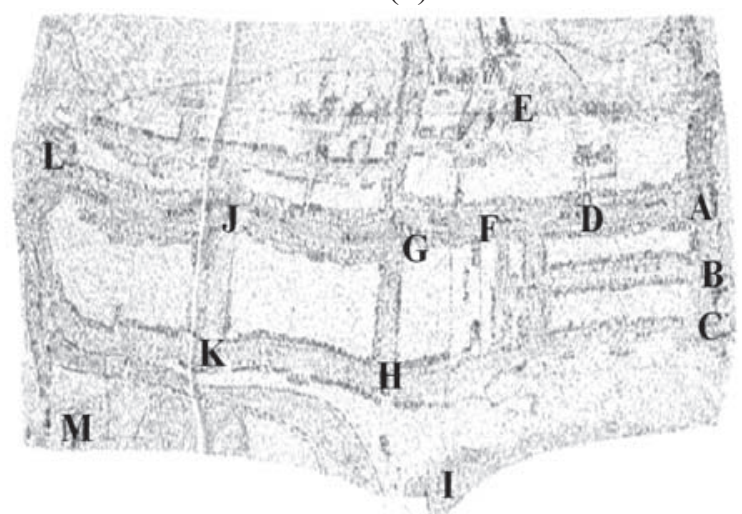

(c)

Fig. 4 The geometric correction of Machiya Drawing: A $\sim$ M 13 correspondence points
(a) current map, (b) Machiya Drawing,
(c) corrected Machiya Drawing

sufficient evidence obtained in the vicinity of the coastline to confirm its location during the Edo period.

\subsection{Historical inquiry fieldwork: "walking" with an old historical drawing}

This fieldwork corresponds to numbers 1) $~ 3$ ) in the educational plans described in the Introduction.

\subsubsection{The fieldwork we conducted}

We mentioned earlier above the existence of some historical old drawings: the Kanbun Drawing, Syotoku Drawing and the Machiya Drawing. The first two of them, provide the name, frontage and depth of the machiya, which are of great value to the researcher. As to the Machiya Drawing (Fig. 4(b)), we do not know its original purpose, but it helps us imagine the townscape at that time.

The Machiya Drawing is in color and shows the roof style of machiya, i.e., tile roofed houses, single-roofed houses and straw-thatched roof houses. We knew the kind of trading that was taking place by analyzing the machiya's name (for example, a lumber merchant, a fish store) contained in the Kanbun Drawing and the Syotoku Drawing. At this point we could better visualize townscape life. We physically walked in the town with the image we could put together in the classroom. We were able to achieve the goal of our fieldwork: to reconstruct more precisely the image of the townscape in the Edo period and to understand the town as it exists today.

In order to conduct historical inquiry fieldwork along the West Country Highway (ADFGJL in Fig. 4) without using a PDA, it was necessary to compare the current map with the Machiya Drawing on a road to confirm the investigator's position and the position relative to the Machiya Drawing (Fig. 4(a), Fig. 4(b)). Though it was necessary to know how both points corresponded, it is still not an easy task for investigators who do not have the expertise of Hometown historians. If it were possible to display (and change) the Machiya Drawing and the current map on PDA, investigators could conduct the fieldwork more effectively.

Thus, to do so, it became necessary to solve the following problem. The geometric correction is critical because the Machiya Drawing is not drawn correctly and geometrically. To correct the Machiya Drawing, one must know the correspondence point of both maps. With the assistance of Hometown historians, we were able to 


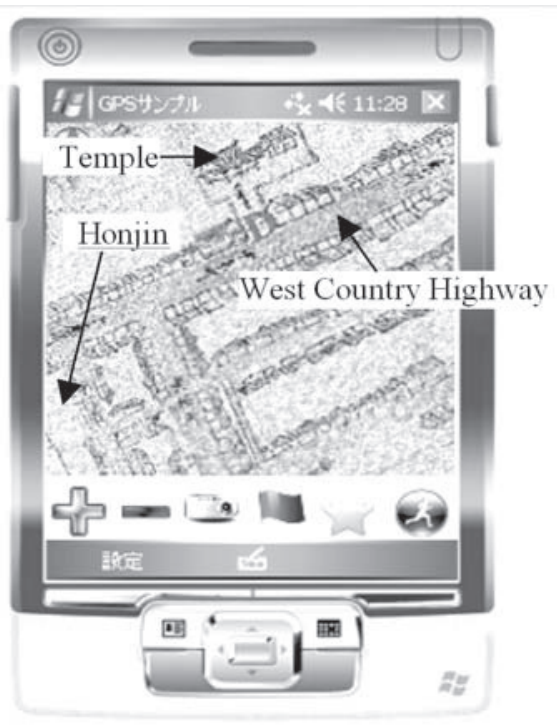

Fig. 5 Machiya Drawing stored in PDA

obtain 13 correspondence points (from A to M in Fig. 4). These points are the intersection of roads, the location of temples and the location of shrines that have not changed from the Edo period to now. The geometric correction of the Machiya Drawing was done by using currently available GIS (Geographic Information System) software, and then storing the corrected version in PDA (Fig. 5).

The investigator could walk the Machiya Drawing road displayed on PDA to confirm his or her current position. He also could change the kind of map on PDA as the need arose. It took about an hour and a half to walk the Machiya Drawing. A part of the route we took is shown in Fig. 6

\subsubsection{The accuracy of the present position of an inves- tigator}

As to the accuracy of the position where an investigator is located on the map, we discuss this using the route data that an investigator followed. Please note that current map shown in Fig. 6(a) is an approximation because the route walked on the road is not precise. Around point $\mathrm{A}$ and point $\mathrm{B}$, the route taken by the investigator deviates somewhat from the path of the road. The measurement is about $7[\mathrm{~m}]$ at most with the exception of a larger error due to poor satellite transmission.

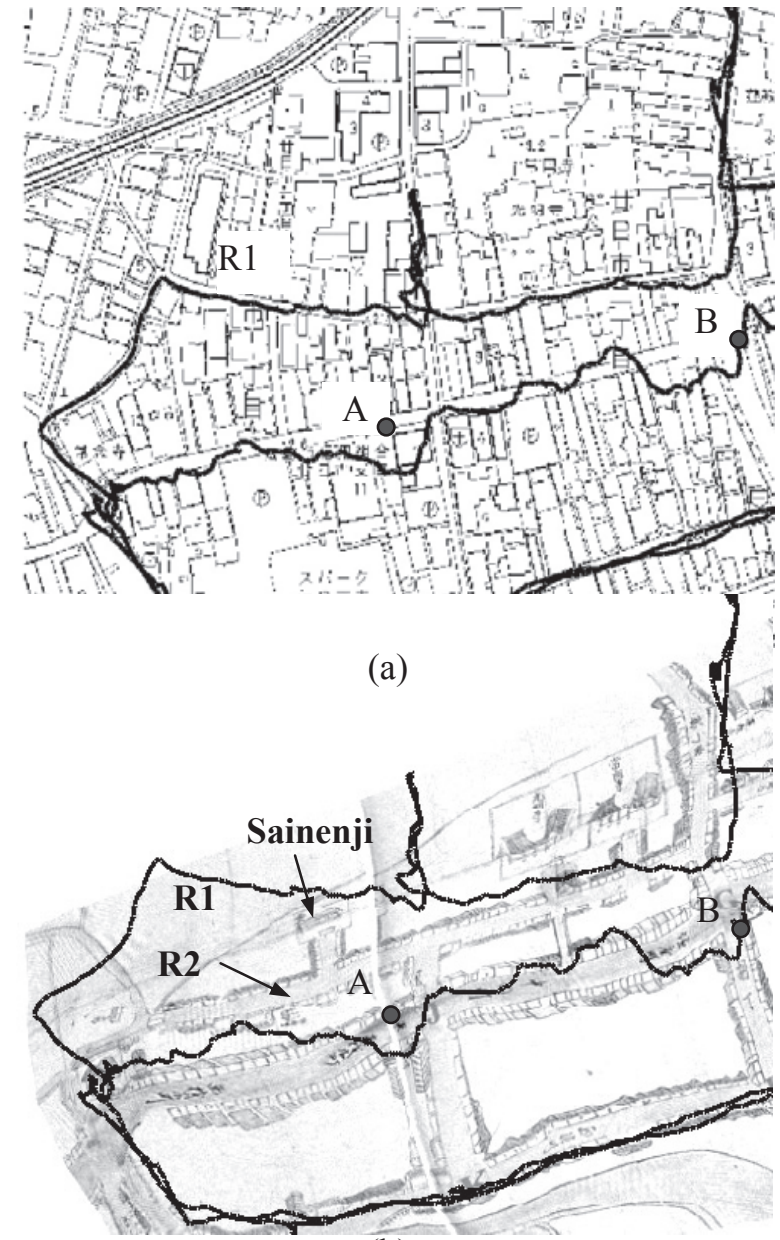

(b)

Fig. 6 The route we took:

(a) Current map, (b) Machiya

Drawing

\subsubsection{The accuracy of the corrected Machiya Drawing}

While using the Machiya Drawing, some problems occurred. The correction for distortion of the Machiya Drawing is insufficient, especially at the area without any corresponding points, because they simply didn't exist with any precision on the Drawing.

We knew from our investigation that the road $\mathrm{R} 1$ on the Machiya Drawing and R2 on the current map are at the same location today as they were in the Edo period. It is one piece of evidence that the road R1 runs toward the northwest as pictured on the oldest Kanbun Drawing of the Edo period. If we had been able to obtain a point of correspondence at the Sainenji Temple (see Fig. 6(b)) or anywhere on the road R1, we could have corrected 
the Machiya Drawing more precisely and geometrically.

However this temple no longer exists here, and is not located on the current map. One problem currently under investigation is to establish the precise location of the temple.

\subsubsection{Evaluation of the fieldwork}

Our fieldwork underscored the fact that there is a big difference between understanding what the town was like in the Edo period while watching Machiya Drawing in the classroom, versus the actual experience of walking the Machiya Drawing in PDA. As indicated earlier, tothirds of the houses were destroyed at the end of the Edo period, and most of the old houses in this district no longer exist. However, it was still possible to simulate what it was like to walk in the town at that time.

In addition, we were able to establish the approximate location of specific houses or buildings that are pictured on the Machiya Drawing but are no longer there, for example, Honjin (an inn for the local lord: Fig. 5), Satuba (a bulletin board: A in Fig. 6) and Ebisusya (a shrine where the god of wealth stays: B in Fig. 6). Our fieldwork was effective for understanding the townscape in the Edo period by overlaying this image in our minds as we viewed the same area that still has some vestiges of the once thriving community of lumber merchants and fish stores depicted in the Machiya Drawing. Some additional points are worth making.

Although the object of this fieldwork was primarily to reproduce the image of the old townscape, we also were able to see that the Sainenji Temple had been moved to another location and could observe and better recognize the detail expression contained in the Machiya Drawing.

The research about correcting old maps and/or old historical drawings can be found in Kojima and Tamagawa (2004), Shimizu et al. (1998, 2008) and Tsukamoto and Isoda (2007).

\section{CONCLUSION}

The merits of the fieldwork we conducted using PDA are 1) students have close acquaintance with IT equipment, 2) carrying a paper map is unnecessary, 3) students do not lose their way or lose track of the area of investigation, 4) it is easy to input the information obtained through fieldwork, 5) just clicking the icon of the camera allows us to record the places where we took pictures, 6) after each group investigates their regions, it is possible to integrate the combined results easily, and, most importantly, 7) we can continue to explore new ways of doing fieldwork based on our findings to date.

Some of the problems of fieldwork we encountered are as follows: 1) It is sometimes difficult but necessary to manage and integrate the operation of PDA and GIS in PC. 2) Occasionally, it is hard to watch the content on the display in outdoor light because brightness is inadequate and the display is small. 3) The location of the investigator might not be at the correct position on the map in PDA. 4) The satellite transmission sometimes might not reach the GPS receiver because of surrounding geographical features, buildings, and climate. 5) During fieldwork, the battery life in PDA is only a few hours because the power supply shut down.

Finally, the educational benefits include the following: 1) Students can create new methods of fieldwork, 2) Students can learn the process by which the collected data are taken into PC, and analyzed by GIS application. 3) Students also learn GIS as a by-product of fieldwork, something that becomes increasingly important because of environmental problems, etc.

We have had a lot of cooperation from local groups and organizations because this research is for the education of students, and our purpose is to contribute something to the region. We were able to obtain some old historical drawings, paintings on folding screens, picture scrolls, other historical materials, city planning documents and the close cooperation from various institutional and academic fields in the region. Students met and communicated with many people in the region through their fieldwork and workshops. They learned a great deal about the region and learned with people in the region. 
Many old historical drawings remain scattered about in Japan, and various groups and professional societies exist in each region to do innovative research on local culture and history. Having said this, we would like to see broader use of our methods that is, learning with people in the region using lots of historical material that can be found in libraries in other cities and regions as well as in Hatsukaich City.

In the remainder of the paper, we describe the contribution of our work the region. The location for doing fieldwork is our home town near the Hiroshima Institute of Technology. It is critical to the successful development of young students to research local culture and history through fieldwork in Hatsukaichi and similar localities. Although we have not described it in detail, we have done some exploratory research on historical problems related to the townscape of the post town in Hatsukaich. Some of our results are worth mentioning. For example we have reconstructed Honjin using the technology of 3DCG (3-dimensional computer graphics) for the first time when only the floor plan is known but the elevation is not.

We made good use of the enormous reference works and files of reference materials that members of Hatsukaichi City Hometown Cultural Society researched and described about the culture and history in this region. For example, we translated material from old historical works into current Japanese documents. Some of our research reports were reprinted in an organ of the Hatsukaichi City Hometown Cultural Society, and then disseminated widely to people in the region. We held workshops that included students, teachers, City Planning Division officials in the Hatsukaichi City Office, Hometown historians, and others, in which we proposed our plans to make the region better based on its history and culture. We look forward to continuing this dialogue and the positive developments that may occur as a result of our pioneering efforts.

\section{ACKNOWLEDGMENT}

T.Miyoshi would like to express my heartfelt appreciation for the great help to translate into a better English of this thesis by Dr. and Mrs. Lynn G. Llewellyn.

\section{REFERENCES}

Abe, N., Hasegawa, N., Koba, K., Moriyasu, K. and Sakai, T. (2004) Development and Evaluation of Information Providing System Using PDA and GPS for Nature Observation. Japan journal of educational technology, 28 (1), 39-47.

Chen, C. and Hsu, T. (2006) Learning Sustainable Development With Mobile Devices. Journal: Geographiedidaktische Forschungen, 42, 115-120.

Feng, Z., Wang, T., Lin, D. and Chern, J. (2006) Improving Effectiveness and Reliability in Geotechnical Investigations with a Personal Digital Assistant. Journal Transportation Research Record: Journal of the Transportation Research Board, 1935, 161-170.

Kojima, M. and Tamagawa, H. (2004) A basic study on providing meanings to distortions in historical maps and construction of their collection models. Theory and Applications of GIS, 12 (1), 23-33.

Mimura, M., Kunifuji, S., Shizuki, B. and Tanaka, J. (2004) Real world oriented Interactive Learning System Based on Digital Pen Devices and PDAs. Information Processing Society of Japan, 46 (9), 2300-2310.

Shimizu, E., Fuse, T. and Nakata, M. (2008) Landscape visualization of Edo city. Journal of infrastructure planning and management, Japan society of civil engineers, D-64(3), 473-492.

Shimizu, E., Fuse, T. and Morichi, S. (1998) A study on geometric correction of historical maps. Journal of infrastructure planning and management, Japan society of civil engineers, IV-44 (625), 89-98.

Tsukamoto, A. and Isoda Y. (2007), Analysis of local distortions in a historical map "Rakuchu-Ezu". Theory and Applications of GIS, 15 (2), 63-73.

(2009 年 7 月 23 日原稿受理, 2009 年 12 月 8 日採用

決定, 2010 年 4 月 26 日デジタルライブラリ掲載) 